\title{
Los estados de excepción: aspectos conceptuales y su desarrollo constitucional en Ecuador
}

\section{The states of exception: Conceptual aspects and their constitutional development in Ecuador}

\section{os estados de exceção: Aspectos conceituais e seu desenvolvimento constitucional no Equador}

LILIANA GONZÁLEZ BeCERRA*

* Abogada, Universidad Libre de Colombia; especialista en Derecho Procesal y en Pedagogía de los Derechos Humanos; magíster en Derecho de Estado con énfasis en Derecho Tributario, Universidad Externado de Colombia. gonzalezbecerraliliana@gmail.com/https://orcid.org/0000-0001-5956-778X DoI: https://doi.org/10.18601/16926722.n18.06 


\title{
Resumen
}

En la época contemporánea, los jefes de Estado, motivados por situaciones de emergencia o crisis, han recurrido con frecuencia a un régimen jurídico y político con el fin de obtener facultades extraordinarias que les permitan mantener el statu quo; esto a través de crear e imponer un orden normativo, económico, tributario y social de "anormalidad". Esa figura, regulada constitucionalmente en casi todos los Estados de este hemisferio, tiene un ancestro remoto, la Roma republicana, y un avance histórico digno de considerarse para entender las dimensiones del concepto. El estado de excepción no puede verse únicamente desde el ángulo político y contemporáneo, más bien, debe ser visto en contexto y a la luz del derecho internacional humanitario que, en últimas, es el sistema que lo nutre, le da forma y límites.

El caso de Ecuador, cuestión casi central en este texto, resulta particularmente llamativo, pues, en su historia reciente (13 años) ha vivido más de un centenar de estados de sitio sin control alguno y, a pesar de contar con un esquema de regulación estructurado, debe ser revisado en aras de entender mejor la complejidad del concepto y sus consecuencias.

Palabras clave: estados de excepción; estados de sitio; poderes extraordinarios del Ejecutivo; sistema jurídico de emergencia; constitucional; derecho internacional humanitario; Ecuador.

\begin{abstract}
In contemporary times, heads of state, motivated by emergency or crises situations, have frequently resorted to a legal and political regime in order to obtain extraordinary powers that allow them to maintain the statu quo; this through creating and imposing a normative, economic, tax and social order of "abnormality" this constitutionally figure regulated in almost all the States of this hemisphere, has a remote ancestor "Republic Rome" and a historical advance worthy of consideration to understand the dimensions of the concept The state of exception cannot be see only from the political and contemporary angle, rather, It must be seen in context and in light of International Humanitarian Law, which is ultimately the system that nourishes it, gives it shape and limits.
\end{abstract}

The case of Ecuador, and almost central issue in this text, is particularly striking, then, in its recent history (13 years) it has lived more than a hundred states of siege without any control and that despite having a structured regulation scheme should be reviewed in order to better understand the complexity of the concept and its consequences.

Key words: States of emergency; states of siege; extraordinary executive powers; emergency legal system; constitutional; international humanitarian law; Ecuador. 


\section{Resumo}

Nos tempos contemporâneos, os chefes de estado, motivados por situações ou crises de emergência, recorrem frequentemente a um regime jurídico e político para obter poderes extraordinários que lhes permitem manter o statu quo; isso através da criação e imposição de uma ordem normativa, econômica, tributária e social de "anormalidade". Essa figura regulada constitucionalmente em quase todos os estados deste hemisfério possui um ancestral remoto "Roma republicana" e um avanço histórico digno de consideração para entender as dimensões do conceito. O estado de exceção não pode ser visto apenas do ponto de vista político e contemporâneo, mas deve ser visto no contexto e à luz do Direito Internacional Humanitário, que é o sistema que o nutre, em última análise, lhe dá forma e limites.

O caso do Equador, uma questão quase central neste texto, é particularmente marcante, pois, em sua história recente (13 anos), mais de cem estados de sítio viveram sem controle e que, apesar de ter um esquema regulatório Estruturado deve ser revisado para entender melhor a complexidade do conceito e suas conseqüências.

Palavras chave: Estados de exceção, estados de sítio, poderes extraordinários do executivo, sistema jurídico de emergência, Constitucional, Direito Internacional Humanitário, Equador.

\section{Introducción}

Para afrontar la pandemia del Covid-19 los países acudieron a regímenes especiales de excepción para que la rama ejecutiva tuviera facultades legislativas, ello con el fin de proferir normas en todos los órdenes, con las cuales dotar de recursos, establecer prioridades y solucionar los problemas sociales y económicos que trajo consigo la situación de emergencia.

Dichos estados de excepción no son una figura política exclusiva de las épocas contemporáneas, son una tradición jurídica que ha avanzado con la humanidad misma, su estudio no se puede abstraer del contexto en el que se presentan, de las circunstancias que los ameritan y de sus limitantes. De tal forma que no es posible comprender su significado tan solo leyendo las medidas adoptadas dentro de ellas.

Así las cosas, el presente artículo analiza los estados de excepción en Ecuador y su aplicación al caso de la pandemia covid-19 en Ecuador. Así, se abordan los elementos históricos y conceptuales de esta figura, para luego dar cuenta de sus retos y dificultades. 


\section{Antecedentes históricos y conceptuales de la figura del estado de excepción}

\section{A. Concepto general de los estados de excepción}

Mucho se ha escrito sobre aquellas "irregularidades" o "anomalías" que irrumpen en el normal desarrollo político, normativo, económico y social de un Estado. Básicamente, estas irregularidades surgen de una emergencia que despierta el poder del soberano, que obliga a su actuar y, finalmente, a ejercer el poder decisorio que permanece en segundo plano, en "normalidad". Lo anterior empuja al soberano a fundar norma y a crear un orden jurídico, actualmente en virtud de los desarrollos constitucionales con limitantes basadas en los derechos humanos, antes, como en el caso del gran Imperio Romano, sin tener en cuenta dichas consideraciones.

En el derecho internacional, por ejemplo, la figura se encuentra claramente definida. El concepto data de 1969, de la Convención Americana sobre Derechos Humanos ("Pacto de San José"), en donde se dice:

En caso de guerra, de peligro público o de otra emergencia que amenace la independencia o seguridad del Estado parte, éste podrá adoptar disposiciones que, en la medida y por el tiempo estrictamente limitados a las exigencias de la situación, suspendan las obligaciones contraídas en virtud de esta Convención, siempre que tales disposiciones no sean incompatibles con las demás obligaciones que les impone el derecho internacional y no entrañen discriminación alguna fundada en motivos de raza, color, sexo, idioma, religión u origen social. (OEA, 1969, art. 27)

Así, tenemos que los estados de excepción son regímenes jurídicos especiales, regulados en la actualidad por las constituciones y por el derecho internacional humanitario (DIH), cuya naturaleza erga omnes se desprende de la necesidad de protección de los derechos humanos. En otras palabras, surgen como medida extrema para proteger el Estado de derecho y los derechos constitucionales de las personas, todo mientras existan circunstancias que los amenacen.

Adicionalmente, cabe señalar que el concepto aquí tratado ha sido denominado de distintas maneras a través del tiempo. De tal forma que "al estado de excepción se le suele asociar con diversas denominaciones o términos tales como, 'estado de sitio', 'plenos poderes', 'poderes de emergencia', 'ley marcial', entre otros, de los cuales se ha llegado a afirmar cierta sinonimia que le ha restado claridad conceptual" (Pavlovich, 2008, p. 48).

\section{B. Desarrollo histórico y contexto}

Tal parece que la necesidad de adoptar medidas para los estados de anormalidad no es exclusiva o propia de épocas contemporáneas, pues esta ha ido evolucionando con la historia 
misma de la humanidad, según su organización político-administrativa y sus concepciones sociales. El antecedente más antiguo de los estados de excepción, según se ha determinado, se encuentra en la época de la República Romana, cuando las medidas adoptadas para proteger al soberano-dictador y al gobierno de facto permanente constituyeron el sustrato legítimo para las restricciones que configuran el concepto.

No puede perderse de vista que, tal como lo menciona Pardo Martínez (2011) en su artículo denominado "Los estados de excepción en el constitucionalismo evolucionario: el caso colombiano", el estado de excepción tiene antecedentes en la figura del dictador romano, teniendo que "el dictador era un magistrado extraordinario, no sometido ni a la provocatio ni a la intercessio de los tribunos" (p. 73). En otras palabras, el dictador no estaba obligado a respetar el principio de legalidad, no se encontraba sujeto a la posibilidad de objeción a sus decisiones, su poder no podía superar el lapso de los seis meses, no era posible que fuese reelegido y era elegido por privilegio de los cónsules, estaba llamado a romper la estructura de los patricios, todos con magistraturas extraordinarias que gobernaban y expedían la ley principalmente, pero que se encontraban supeditados los unos a los otros. Así, cuando llegaban los desórdenes públicos, las invasiones o la guerra, se entendía que se suscitaban circunstancias sobrevinientes y peligrosas que obligaban a adoptar medidas urgentes. Es entonces, temporalmente, cuando el dictador tomaba el poder para proteger el Estado y sin temor alguno por mantener una buena imagen pública salvaba del caos al Estado mismo, suspendiendo las libertades ciudadanas y controlando la situación. Nótese que los cónsules elegidos se apartaban del gobierno separándose del poder, resguardándose, "cedían el puesto" a este magistrado único. Es aquí cuando empezamos a notar diferencias significativas con la estructura de la figura actual, pues no es el soberano quien asume las decisiones, allá en la antigua Roma, surgía otra figura encargada de asumir el poder y solucionar el peligro.

Como puede leerse, en la Edad Antigua se respondía a los estados de crisis con bastante energía, sin limitaciones, a tal punto que incluso el derecho a la la vida quedaba suspendido durante la dictadura.

Posteriormente, durante la Edad Media, se podría decir que el estado de excepción era algo permanente, aseveración que procedo a explicar brevemente: sí existía para entonces un poder que se encontraba en cabeza y a la vez controlado al extremo por una figura que encarnaba en sí misma una potestad suprema, ilimitada, derivada de abolengos y delegaciones divinas que le permitían la dominación de una clase sobre otra y la adopción de toda clase de decisiones políticas, económicas, sociales y administrativas, dependiendo de cualquier situación. Ello ocurría no solo en caso de anormalidad, pues no había necesidad de romper una estructura jurídica de tranquilidad para poder solucionar una crisis; asimismo, dicha figura se encontraba facultada por Dios o por el papa para proceder según su parecer ante las situaciones que llegaran a suceder; por lo que la figura se camufla en el devenir normal de las estructuras de poder y no depende de disrupciones históricas o momentos de crisis. 
El recorrido histórico pretendido lleva al tema a un hito importante del siglo xx: la Alemania nazi, el partido Nacionalista Obrero Alemán y su ideología. Es obligatorio, al tratar de abordar el tema, referirse al concepto desarrollado por el jurista, filósofo y político alemán Carl Schmitt. Este militante destacado del partido nazi, considerado por la SS (Schutzstaffel) como advenedizo, adscrito a la escuela del llamado realismo político y a la teoría del orden jurídico, quien rechazó la autofundación del orden jurídico y se distanció de Kelsen al encontrar en la decisión política el vehículo entre la racionalidad jurídica y la positividad de las reglas del derecho. Según él, la guerra, la decisión y el soberano son elementos indispensables por considerar en esa regulación anormal producida en contextos de "anormalidad" (Gerhardt, 2003).

Si el detonante del estado de excepción son las circunstancias que sacan a un Estado de una tranquilidad normativa por una decisión soberana, podría entonces concluirse en un silogismo claro: que esto sucede porque el orden jurídico existente no comporta la regulación necesaria para afrontar la emergencia, lo que nos pone frente a otro tratadista importante, el filósofo italiano Giorgio Agamben, nacido en 1942, quien en su obra Estado de Excepción nos sitúa de nuevo en la "dualidad" del desarrollo conceptual del tema, connotación tan mencionada, que comporta una doble correspondencia del estado de emergencia, es decir, si este corresponde a un tema del derecho público o es un hecho jurídico en sí, si se trata de lo normal dentro de lo anormal y si debe considerarse a los enemigos y amigos del Estado (Agamben, 2003).

Llegados a este punto, es necesario relacionar los pensamientos de los dos autores mencionados para contextualizar el estado de emergencia a la luz de ellos. Agamben, por un lado, fundamenta o explica de forma robusta ese poder de decisión, tan significativo en Schmitt, que sin duda es el punto de partida en los estados de excepción; Agamben lo hace dentro de un sustrato cuya naturaleza es la necesidad.

Pero aquella tiene ya un decantado recorrido en la filosofía política. Fue tratada en el Decreto de Graciano (Decretum Gratiani) también conocido como Concordantia Discordantium Canonum y terminado en 1140, en la premisa "necessitas legem non habet" ("la necesidad no tiene ley"). Asimismo, la necesidad fue también objeto de disertaciones en el derecho de los príncipes en Santo Tomás de Aquino. La necesidad, entonces, son hechos, realidades y circunstancias que rompen el desarrollo tradicional del Estado, lo sacan de lo habitual y lo llevan al caos. No puede ser un hecho sin importancia, debe ser en sí mismo un hecho extraordinario (que según la definición de la Real Academia de la Lengua Española [2019] significa: "Fuera del orden o regla natural o común"). La necesidad creada por la emergencia debe ser de tal envergadura que rompe la normalidad y obliga a crear un nuevo orden jurídico.

Entonces, tenemos que debe quebrarse el orden jurídico y vulnerarse el tan anhelado principio de seguridad jurídica, ya que, como se mencionó, el desarrollo jurídico de un Estado se hace para tiempos de no alteración, para épocas de ángeles o mejor, para tiempos de tránsitos en sociedades sin grandes baches. Toda la construcción legal y el desarrollo normativo: formal, impersonal y abstracto que rige en un tiempo y espacio, choca de 
frente con un gran obstáculo, que además de romper esas medidas de conducta, las hace inoperantes para conjurar la crisis, les arrebata los poderes de aplicabilidad y pertinencia, hace que el sistema jurídico sea tan solo un obstáculo más para retomar al equilibrio. Lo anterior se torna problemático ya que en virtud del contrato social los integrantes del conglomerado cedimos libertad a cambio de equilibrio, paz, bienestar y convivencia tranquila, entonces, el propósito que tiene la institución político-administrativa no se estaría cumpliendo. Es allí cuando llega el momento de interrumpir el funcionamiento legislativo y encender la creación productora de normas; producción acorde, apropiada y eficiente (Fijalkowski, 1966).

Si el dirigente, el representante de las voluntades soberanas del pueblo (ya no el dictador romano), la persona que detenta el poder político, conductor natural del Estado, se topa con el gran obstáculo ya mencionado, se ve obligado, en virtud de la representación que posee (que a la vez le obliga y legítima en la causa), a tomar la decisión que es, de acuerdo con Schmitt, la soberanía misma, pues es esa capacidad de decidir el ejercicio real de la soberanía, es allí donde radica y cuando se produce ante la amenaza a la unidad que representa para los elementos del Estado.

El soberano elegido democráticamente, enmarcado dentro de la división tripartita del poder o, mejor, dentro de la estructura organizada del Estado de derecho, decide irrumpir en la seguridad jurídica para crear un orden con las medidas exactas del momento y la realidad, con las respuestas mediáticas a la emergencia. Ahí está ejerciendo para muchos un poder injusto o ilegal (contrario a la ley) o una dictadura (Schmitt, 1922) a la que tiene derecho. Un derecho que detenta pura y simplemente, un derecho que debe ejercer. Así lo expresa Wilmar Martínez Márquez al afirmar: "Dictadura que, cabe aclarar, al estar sustentada en la defensa de la comunidad de los amigos, es decir, en la defensa del modo de estar y ser de una comunidad determinada, no es contraria al Derecho, sino una garantía para su continuidad" (2009, p. 60).

El dueño del poder de decisión manifiesta su poderío y asume su posición no convencional de legislador para derrotar la amenaza, todo en aras de proteger al pueblo. Ahí surgen las herramientas de demolición del obstáculo, surge también la ley al servicio del contexto histórico (papel que no se ha discutido nunca, ya que la ley es propia del contexto en que se circunscribe), pero esta vez, movida por la urgencia de ser producida por quien no está llamado en normalidad a hacerlo, por quien no es su génesis natural. De ahí lo ya mencionado de la dictadura comisional. Así, dicha persona dotada ahora de una gigantesca facultad se erige a sí misma (con sus aliados de gabinete) como la fuerza política y jurídica que combate la emergencia, sobre ese ser, entendido como gobierno, recae toda la responsabilidad de lo que suceda en su territorio, en su país y en las fronteras de su mandato otorgado por aquellos a quienes debe proteger por ser su representante.

Llegados a este punto y utilizando un método deductivo podría decirse, entonces, que en virtud de una "necesidad” (respondiendo a la pregunta ¿cuándo?), cuya naturaleza sirve como dispositivo detonante, del hecho real que origina todo este movimiento se va a la “decisión” (¿cómo?), tomada por el "soberano” (¿quién?) para solucionar la circunstancia 
grave que amenaza al Estado mismo a través de la promulgación de un nuevo orden jurídico aplicable, no ya aquel fuera de contexto que no corresponde a lo que vive el pueblo (¿por qué?), todo esto dentro de un espacio geográfico y político-administrativo determinado (¿dónde?) en el que se produce la anormalidad y de donde es soberano al ahora ejecutivo-legislador

A este concepto elaborado a partir del trabajo de grandes ideólogos debe sumársele otra pregunta: ¿en qué condiciones? Es así como podemos trasladarnos a la Edad Contemporánea en donde todas estas teorías tienen como molde la ley o la constitución.

Es justamente en las constituciones locales de los Estados Unidos de América, que las incorporaciones normativas de los estados marciales -ya mencionadas en la Declaración de los Derechos del Hombre y del Ciudadano de 1789 en Francia- fueron añadidas a la carta de 1791 (Ley de 10 de julio), todo esto en el marco del constitucionalismo clásico. Asimismo, es de allí de donde se inspiró la Carta de Cádiz de 1812 y en donde, junto con las ya mencionadas cartas políticas, se puede rastrear el antecedente de las constituciones latinoamericanas y de la regulación de la figura jurídica que aquí nos compete.

Con el tiempo, la concepción política y jurídica que en principio erigía al mecanismo excepcional para responder a la intranquilidad por inminentes peligros creados en razón de la guerra exterior o por desórdenes internos terminó siendo la maniobra utilizada para la protección del soberano y su poder, su orden y, por ende, el estado de emergencia o el estado de sitio. Ahora bien, para ir introduciendo algunos elementos adoptados en ciertas épocas de la historia de la figura se dice que esta es: "la ruta velada para insertar por la ruta constitucional el germen del autoritarismo o absolutismo, por medio de reglas que rompen el equilibrio y propician la restricción a las libertades y principios consagrados por el colectivo social de un Estado en la norma suprema" (Silva, 2016, p. 49).

No puede perderse de vista que, como aducen los presidentes contemporáneos, si se estuviera frente a un Estado constitucional puro, simplemente no sería posible acudir justificadamente en repetidas ocasiones al mecanismo de excepción y someter a los pueblos a lo que este implica. Por lo que en la doctrina se ha mencionado que los Estados tienen regímenes mixtos ante el presidencialismo de emergencia o se han catalogado como pseudoconstitucionalistas.

Lo que sí está demostrado por el análisis de los acontecimientos y hechos que constituyen el desarrollo de la humanidad de la Edad Contemporánea, es que la figura, tan usada, debe poseer límites. Esta no se concibió ilimitadamente, no tiene un desarrollo discrecional, sino reglado y siempre tendiente a la finalidad del restablecimiento "expedito" de la normalidad.

Lo cual es aceptado por la concepción internacional con enfoque de derechos humanos y, tal como se mostró supra, esas limitantes componen parte de la definición estructurada desde 1969, donde se le impone una faja al estado de sitio, pero, dicho sea de una vez, en un territorio en que gran parte de sus pueblos han vivido en permanentes restricciones a sus libertades por causa de las declaratorias frecuentes, en la segunda mitad del siglo xx, del "toque de queda" (término que también ha sido usado como sinónimo incorrectamente). 
Todo ello en un cono donde la figura ha sido parte del imaginario colectivo y ningún ciudadano, por más joven que sea, se ha visto ajeno a ella. En nuestra hermosa Latinoamérica, la faja ha ceñido poco, tal como lo planteó Haba en 1986:

... así como en el plano ideológico es la doctrina de la seguridad nacional quien provee las justificaciones habituales para otorgar al aparato estatal facultades que le permitan violar cómodamente los derechos humanos; en el plano jurídico institucional ello suele darse -y a menudo invocando aquella- en el marco de los estados de excepción o emergencia (llamados así o de otras maneras). (p. 651)

Así lo puede ver el que sin mayor esfuerzo busque en la literatura histórica, por ejemplo, las terribles épocas vividas en estados de sitio en Chile. Infortunadamente, América Latina ha sido utilizada por los estudiosos como experimento de ensayo y error de la figura aquí tratada, ya que en la mayoría de las constituciones de los Estados, si no en todas, está regulada, pero la faja se desdibujó, el sacrificio de unos derechos (como la libertad de locomoción) para preservar otros de mayor jerarquía (como la vida) es ciencia ficción para algunas generaciones del cono sur.

\section{Limitaciones a los estados de excepción}

A este punto nos ha llevado el desarrollo del tema y, así, al cuestionamiento ¿de qué forma?, no puede dársele una respuesta simple, ya que un tratamiento juicioso del tema implica tocar una fibra dolorosa y compleja de lo que somos como pueblo. No puede entonces decirse que la forma de la figura está dada por la faja llamada constitución, excepto si se incorpora la concepción del bloque de constitucionalidad del que forman parte (como se debe entender desde el primer año de básica primaria) los tratados y convenios internacionales de derechos humanos.

El ejercicio de delimitar el estado de excepción que se presenta a continuación, se hace junto con la subsunción al sistema de regulación aplicable de protección de los derechos humanos desarrollado por la Organización de las Naciones Unidas (ONU), el Pacto Internacional de Derechos Civiles y Políticos (PIDCP) y, en el ámbito del sistema interamericano de protección de tales derechos desarrollado por la Organización de los Estados Americanos (OEA), la Convención Americana sobre Derechos Humanos (CADH).

Teniendo presente que la naturaleza de las disposiciones del sistema obliga a sus miembros a aplicar criterios de interpretación restrictiva de las mismas, lo que en concreto sujeta al Estado a aplicar aquellas medidas que en menor grado afectan los derechos de las personas. En ese contexto, las limitaciones existentes podrían plantearse de la siguiente forma:

1. En cuanto a la declaratoria: debe cumplirse con los requisitos exigidos en la constitución o en la norma estatutaria, con el fin de hacer público el inicio del estado de sitio, nacional e internacionalmente (PIDCP, art. 4). 
2. En cuanto a su duración: el tiempo de mantenimiento de las medidas es muy importante, debe estar establecido en la constitución; la característica de la temporalidad que se pasa a la permanencia es una de las más frecuentes amenazas a la figura misma, en algunos casos llegó a superar los años, incluso a pesar de haberse dado la suspensión este, lo que origina tiempos de excepción de facto.

3. En cuanto a la emergencia: no todas las circunstancias originan la crisis; hay realidades que pueden manejarse con el ordenamiento interno; la declaratoria debe obedecer en realidad a la necesidad sin forzar, mentir o sobredimensionar los fenómenos originarios, observando los principios de necesidad y proporcionalidad.

4. En cuanto a las medidas adoptadas: si se realizó la proclamación oficialmente y se indica su temporalidad, debe dar a conocer el conjunto de medidas adoptadas de igual forma.

En el sistema de protección de derechos está permitida la suspensión de algunos de estos. No obstante, hay otros que no pueden ser objeto de dicha suspensión sin importar la gravedad de la situación, son aquellos intangibles o inderogables, derechos que son considerados por un sector doctrinal como normas de ius cogens, estos son: el derecho a la vida (PIDCP, art. 6; $\mathrm{CADH}$, art. 4); el derecho a la integridad personal (PIDCP, art. 7; CADH, art. 5); la prohibición de la esclavitud y servidumbre (PIDCP, art. 8, párrs. 1 y 2; CADH, art. 6); la prohibición de ser encarcelado por incumplimiento de una obligación contractual (PIDCP, art. 11); el principio de legalidad (PIDCP, art. 15; CADH, art. 9); el derecho al reconocimiento de la personalidad jurídica (PIDCP, art. 16; CADH, art. 3); el derecho a la libertad de pensamiento, conciencia y religión (PIDCP, art. 18; CADH, art. 12); la protección a la familia (CADH, art. 17); el derecho al nombre ( $\mathrm{CADH}$, art. 18); los derechos del niño (CADH, art. 19); el derecho a la nacionalidad (CADH, art. 20); los derechos políticos (CADH, art. 23).

5. En cuanto al ejercicio de las funciones dentro de las ramas del poder público: la separación e independencia de poderes muta, como es lógico, por las facultades exorbitantes del ejecutivo. No obstante, el órgano judicial debe conservar la independencia y mantener su carácter civil ya que definitivamente los tribunales militares no pueden juzgar civiles y ser la voz de los derechos de todos ante la arbitrariedad.

6. Mal hubiera estado la prohibición de adoptar medidas que suspendan cierto tipo de derechos si no se hubiera concebido la prohibición de suspensión de los mecanismos de protección de los mismos, las garantías judiciales como el recurso de habeas corpus o exhibición personal, el de amparo y los principios del debido proceso, tal como la presunción de inocencia, que permitan dar opciones a la ciudadanía frente a aberrantes desmanes como las detenciones arbitrarias; por ende, debe garantizarse que los jueces (en sentido amplio), ejerzan sus labores y sus potestades.

7. Veeduría internacional: una vez se haya dado la proclamación oficial o declaratoria (numeral 1 de este listado) el Estado debe informar inmediatamente a los demás Estados partes, tanto del PIDCP y como de la $\mathrm{CADH}$, por conducto del Secretario General de las Naciones Unidas (PIDCP, art.4.3) y del Secretario General de la OEA (CADH, art. 
27.3) relacionando las medidas adoptadas, los motivos de la adopción y anexando la documentación completa sobre las disposiciones jurídicas pertinentes, información que complementará a lo largo del fenómeno, con las que se generen posterior a esa primera etapa.

Con esto se activa el actuar del veedor del Comité de Derechos Humanos, quien es llamado a evaluar si las medidas tomadas por el Estado parte eran las estrictamente requeridas y proporcionales a la emergencia y, de otra parte, inicia la posibilidad para los Estados parte de vigilar el cumplimiento de las disposiciones del Pacto (OACNUDH, 2013).

\section{EI derecho de excepción en Ecuador}

La institución jurídica que a este punto del documento se ha contextualizado es denominada en Ecuador como estado de excepción, ello con la entrada en vigencia de la Constitución de 2008. Ahora bien, como se mencionó, esta es una figura que a lo largo de la historia ha tenido otras denominaciones, tales como: facultades extraordinarias, estados de urgencia, Estado de Sitio y Estado de Emergencia.

En concreto, la Corte Constitucional de Ecuador la definió como una figura jurídica (potestativa del Estado) que se ejerce para resolver problemas de una situación no previsible al tiempo de defender los derechos humanos de los ciudadanos: "que [...] no pueden ser garantizados con los mecanismos ordinarios establecidos en la Constitución y en la ley. El Estado utiliza, entonces, esta figura jurídica para solventar crisis extraordinarias y emergentes" (Corte Constitucional de Ecuador, 2008, sentencia 001-08-SEE-CC). La Ley de Seguridad Pública y del Estado en Ecuador (2009) los establece como "la respuesta a graves amenazas de origen natural o antrópico que afectan a la seguridad pública y del Estado. [...] es un régimen de legalidad y por lo tanto no podrán cometer arbitrariedades a pretexto de su declaración" (art.30).

Ambas definiciones desconocen aspectos importantes en su redacción, pero podrían complementarse perfectamente; no obstante, cabe señalar que la precisión en la denominación no será objeto de este artículo.

El recorrido histórico constitucional de los estados de sitio en Ecuador puede verse a grandes rasgos en la tabla 1.

Tabla 1. Desarrollo constitucional del derecho de eXCEPCión en Ecuador

\begin{tabular}{|c|l|l|l|}
\hline Norma constitucional & Denominación & $\begin{array}{l}\text { Situaciones de emer- } \\
\text { gencia contempladas }\end{array}$ & \multicolumn{1}{|c|}{ Procedimiento para la adopción } \\
\hline Constitución 1835 (art. 64) & $\begin{array}{l}\text { Invasión exterior o con- } \\
\text { moción interna }\end{array}$ & $\begin{array}{l}\text { El Ejecutivo ante el Congreso o ante el } \\
\text { consejo de gobierno en receso de aquel } \\
\text { informaba la situación, se calificaba el peli- } \\
\text { gro y se le dotaba de facultades para actuar. }\end{array}$ \\
\hline
\end{tabular}




\begin{tabular}{|c|c|c|c|}
\hline Norma constitucional & Denominación & $\begin{array}{l}\text { Situaciones de emer- } \\
\text { gencia contempladas }\end{array}$ & Procedimiento para la adopción \\
\hline $\begin{array}{l}\text { Constitución } 1850 \text { (arts. } 60 \\
\text { y 61) }\end{array}$ & & $\begin{array}{l}\text { En casos de grave pe- } \\
\text { ligro por conmoción } \\
\text { interior y amenaza a } \\
\text { la seguridad pública y } \\
\text { guerra exterior }\end{array}$ & $\begin{array}{l}\text { El Ejecutivo previa autorización de la } \\
\text { Asamblea Nacional }\end{array}$ \\
\hline $\begin{array}{l}\text { Constitución } 1869 \text { (arts. } 60 \\
\text { y 61) }\end{array}$ & Estado de sitio & $\begin{array}{l}\text { Ataque externo o con- } \\
\text { moción interna }\end{array}$ & $\begin{array}{l}\text { El Ejecutivo previa autorización del Con- } \\
\text { greso o del Consejo de Estado }\end{array}$ \\
\hline Constitución 1906 (art. 83) & & $\begin{array}{l}\text { Amenaza inminente, } \\
\text { invasión exterior, gue- } \\
\text { rra internacional, con- } \\
\text { moción interior a mano } \\
\text { armada }\end{array}$ & $\begin{array}{l}\text { El Ejecutivo presenta informe al Congreso } \\
\text { o al Consejo de Estado, en su ausencia, } \\
\text { estos últimos evaluaban la situación, si la } \\
\text { encontraban justificada facultaban el uso } \\
\text { de medidas extraordinarias }\end{array}$ \\
\hline Constitución 1967 (art. 185) & Estado de sitio & $\begin{array}{l}\text { Conmoción interior o } \\
\text { conflicto exterior }\end{array}$ & $\begin{array}{l}\text { El presidente, con autorización del Congre- } \\
\text { so, podría asumir facultades especiales; en } \\
\text { la ausencia de este la podía declarar por sí } \\
\text { mismo. Incluyó la declaratoria oficial, el } \\
\text { control del Tribunal de Garantías Consti- } \\
\text { tucionales, los derechos que no podían ser } \\
\text { suspendidos y la posibilidad del Congreso } \\
\text { de dar por terminado el estado de sitio } \\
\text { al desaparecer las circunstancias que lo } \\
\text { motivaron. }\end{array}$ \\
\hline Constitución 1978 (art. 78) & $\begin{array}{l}\text { Estado de } \\
\text { emergencia }\end{array}$ & $\begin{array}{l}\text { Agresión externa, gue- } \\
\text { rra internacional, grave } \\
\text { conmoción o catástrofe } \\
\text { interna }\end{array}$ & $\begin{array}{l}\text { El presidente notifica a la Cámara Nacional } \\
\text { de Representantes o al Tribunal de Ga- } \\
\text { rantías Constitucionales quienes también } \\
\text { podrían revocar la declaratoria. Conserva } \\
\text { la estipulación de las garantías constitucio- } \\
\text { nales preservadas }\end{array}$ \\
\hline $\begin{array}{l}\text { Constitución } 1998 \text { (Cap. IV } \\
\text { arts. } 180 \text { y ss.) }\end{array}$ & $\begin{array}{l}\text { Estado de } \\
\text { emergencia }\end{array}$ & $\begin{array}{l}\text { Inminente agresión ex- } \\
\text { terna, guerra internacio- } \\
\text { nal, grave conmoción } \\
\text { interna o catástrofes } \\
\text { naturales }\end{array}$ & $\begin{array}{l}\text { Además de lo que viene de la anterior } \\
\text { Constitución, se incorporó la posibilidad de } \\
\text { ser declarada en todo el territorio o en parte }\end{array}$ \\
\hline $\begin{array}{l}\text { Constitución de } 2008 \text { (Cap. } \\
\text { III, sección IV, art. 164) }\end{array}$ & $\begin{array}{l}\text { Estado de } \\
\text { excepción }\end{array}$ & $\begin{array}{l}\text { Agresión, conflicto ar- } \\
\text { mado internacional o } \\
\text { interno, calamidad pú- } \\
\text { blica o desastre natural }\end{array}$ & Regulación actual \\
\hline
\end{tabular}

Fuente: elaboración propia.

\section{A. Elementos constitucionales actuales de los estados de excepción en Ecuador}

La figura conserva una estructura similar a la tradicional en las constituciones latinoamericanas, está regulada por la Constitución de la República del Ecuador, que es la norma jurídica suprema vigente del país, que rige desde el 20 de octubre de 2008, con tendencia garantista y neoconstitucionalista. Esta Constitución cambió el modelo estatal de Estado social a Estado constitucional de derechos y justicia, el texto fue redactado por la 
Asamblea Nacional Constituyente que sesionó entre 2007 y 2008, para luego ser sometido a referéndum constitucional, y fue aprobado con el 63,93\% de los votos válidos.

TABLA 2. NoRMatividad BASE DEL ESTADO DE SITIO Y SUS CONCORDANCIAS

\begin{tabular}{|l|l|}
\hline \multicolumn{1}{|c|}{ Norma base } & \multicolumn{1}{c|}{ Publicación } \\
\hline Constitución de 2008 & Registro Oficial 449 de 20 de octubre de 2008 \\
\hline $\begin{array}{l}\text { Ley Orgánica de Garantías Jurisdiccionales y Control Cons- } \\
\text { titucional (LOGJCC) }\end{array}$ & $\begin{array}{l}\text { Registro Oficial 52 de 22 de octubre de 2009 - Se- } \\
\text { gundo Suplemento }\end{array}$ \\
\hline Ley de Seguridad Pública y del Estado Ecuatoriano & Registro Oficial 35 de 28 de septiembre de 2009 \\
\hline
\end{tabular}

Fuente: elaboración propia.

\section{ELEMENTOS CONSTITUCIONALES DEL RÉGIMEN}

a. Definición: potestades que la presidenta o el presidente de la República podrán poseer para adoptar medidas en todo el territorio nacional o en parte de él en caso de circunstancias extraordinarias, sin que su acaecimiento interrumpa el desarrollo de las actividades funcionales del Estado y exima a los servidores públicos de la responsabilidad que los abusos cometidos durante el Estado de Excepción generen.

b. Situaciones de crisis: agresión, conflicto armado internacional o interno, grave conmoción interna, calamidad pública o desastre natural.

c. Principios que orientan: necesidad, proporcionalidad, legalidad, temporalidad, territorialidad y razonabilidad.

d. Requisitos de la declaratoria: cuando se declare, debe determinarse la causal y su motivación, el ámbito territorial de aplicación, el periodo de duración, las medidas que deberán aplicarse, los derechos que podrán suspenderse o limitarse y las notificaciones que correspondan de acuerdo con la Constitución y los tratados internacionales.

e. Derechos que pueden suspenderse o limitarse: la inviolabilidad del domicilio, la correspondencia, la libertad de tránsito, de asociación, de reunión e información.

f. Potestades presidenciales durante el Estado de Excepción:

- Decretar la recaudación anticipada de tributos.

- Utilizar los fondos públicos destinados a otros fines, excepto los correspondientes a salud y educación.

- Trasladar la sede del gobierno a cualquier lugar del territorio nacional.

- Disponer censura previa a la información de los medios de comunicación social, que guarde estricta relación con los motivos del estado de excepción y la seguridad del Estado.

- Establecer como zona de seguridad todo o parte del territorio nacional. 
- Disponer el empleo de las Fuerzas Armadas y de la Policía Nacional y llamar a servicio activo a toda la reserva o a una parte de ella, así como al personal de otras instituciones.

- Disponer el cierre o la habilitación de puertos, aeropuertos y pasos fronterizos.

- Disponer la movilización y las requisiciones que sean necesarias, así como decretar la desmovilización nacional cuando se restablezca la normalidad.

g. Procedimiento para la notificación oficial: la cabeza del gobierno, una vez evaluadas las circunstancias, es la encargada de elaborar el documento que contenga la declaratoria con los requisitos ya expuestos, lo firma y dentro de las 48 horas siguientes notificará la declaración a la Asamblea Nacional, a la Corte Constitucional y a los organismos internacionales que corresponda.

h. Duración: mientras dure la emergencia, con 60 días de plazo máximo, renovable por 30 días más, previa notificación.

i. Causales de revocación: cuando las circunstancias lo determinen a juicio de la Asamblea Nacional en cualquier tiempo sin perjuicio del pronunciamiento que sobre su constitucionalidad pueda realizar la Corte Constitucional.

j. Causales de caducidad: si el presidente no renueva el decreto de Estado de Excepción o no lo notifica, este se entenderá caducado al culminar el plazo establecido en la declaratoria.

k. Terminación: por cualquiera de los dos puntos expresados anteriormente y cuando las causas que motivaron el estado de excepción desaparezcan, la presidenta o el presidente lo darán por terminado y notificarán inmediatamente con el informe correspondiente.

Además, como se ha dicho, el estado de emergencia debe estar delimitado y se han creado controles para ello. En el caso ecuatoriano, el derecho constitucional faculta a dos órganos para controlar los decretos que contienen estados de excepción:

a. Asamblea Nacional: órgano del Poder Legislativo, es un parlamento unicameral, formado por 137 asambleístas (la Constitución y el Código de la Democracia establecen su conformación, así: 15 asambleístas elegidos en circunscripción nacional, 2 por cada región autónoma, 2 asambleístas por cada provincia y distrito metropolitano más uno por cada 200.000 habitantes o fracción que supere los 150.000 , y 6 asambleístas por los migrantes); ellos, en su calidad de representantes de sus territorios, ejercen el control político, con las facultades ya mencionadas.

b. El segundo es el control constitucional, que es efectuado por la Corte Constitucional. Tema tratado a continuación.

\section{Control constitucional DEL DECRETO}

El control constitucional del documento normativo por medio del cual se decreta el Estado de Emergencia debe ser controlado por el máximo órgano de vigilancia de la supremacía 
de la Constitución, por eso, la Ley Orgánica de Garantías Jurisdiccionales y Control Constitucional (2009) establece que la Corte Constitucional deberá realizar un control formal y material constitucional automático de los decretos que declaren un estado de excepción $\mathrm{y}$ de los que se dicten con fundamento en este.

\subsection{Control formal}

La Corte debe, en primer lugar, verificar que la declaratoria formal se haya surtido mediante decreto y que aquel cumpla con las formalidades que establece el sistema jurídico, además de que tampoco sobrepase las competencias materiales, espaciales y temporales de los estados de excepción (Ley Orgánica de Garantías Jurisdiccionales y Control Constitucional de 2009, art. 122).

En total concordancia con la CRE, el control se encamina a que estas cumplan con los siguientes requisitos:

- Identificación de los hechos y de la causal constitucional que se invoca.

- Justificación de la declaratoria.

- Ámbito territorial y temporal de la declaratoria.

- Derechos que sean susceptibles de limitación, cuando fuere el caso.

- Las notificaciones que correspondan de acuerdo con la Constitución y los Tratados Internacionales (Ley Orgánica de Garantías Jurisdiccionales y Control Constitucional, 2009 de art. 120).

En caso de que el presidente dentro de las 48 horas siguientes a la firma del decreto no lo remita, la Corte lo conocerá de oficio (Ley Orgánica de Garantías Jurisdiccionales y Control Constitucional de 2009, art. 124).

\subsection{Control material}

En cuanto a la declaratoria, la Corte debe revisar si:

- Los hechos alegados en la motivación hayan tenido real ocurrencia.

- Que los hechos constitutivos de la declaratoria configuran una agresión, un conflicto armado internacional o interno, grave conmoción interna, calamidad pública o desastre natural.

- Que los hechos constitutivos de la declaratoria no puedan ser superados a través del régimen constitucional ordinario.

- Que la declaratoria se decrete dentro de los límites temporales y espaciales establecidos en la Constitución de la República (Ley Orgánica de Garantías Jurisdiccionales y Control Constitucional de 2009, art. 121). 
Así, el control material de las medidas adoptadas requiere que la Corte, con base en la realidad del Estado, verifique lo siguiente:

- Que sean estrictamente necesarias para enfrentar los hechos que dieron lugar a la declaratoria y que las medidas ordinarias sean insuficientes para el logro de este objetivo.

- Que sean proporcionales al hecho que dio lugar a la declaratoria.

- Que exista una relación de causalidad directa e inmediata entre los hechos que dieron lugar a la declaratoria y las medidas adoptadas.

- Que sean idóneas para enfrentar los hechos que dieron lugar a la declaratoria.

- Que no exista otra medida que genere un menor impacto en términos de derechos y garantías.

- Que no afecten el núcleo esencial de los derechos constitucionales, y se respete el conjunto de derechos intangibles.

- Que no se interrumpa ni se altere el normal funcionamiento del Estado (Ley Orgánica de Garantías Jurisdiccionales y Control Constitucional de 2009, art. 123).

Cabe en este punto mencionar que dentro de la legislación ecuatoriana se estipula que los decretos expedidos mediante el uso de las facultades extraordinarias del Ejecutivo por esas "condiciones de anormalidad", son precisamente los decretos ejecutivos con las condiciones que implican.

\section{LOS RECIENTES ESTADOS DE EXCEPCIÓN EN ECUADOR}

Finalmente, para los ecuatorianos, el estado de excepción, el toque de queda, la declaratoria de emergencia y las restricciones a las libertades civiles son más comunes que extraordinarias. Los presidentes han utilizado la figura en bastantes ocasiones, lo que ha permitido toda suerte de medidas legislativas económicas, sociales y tributarias que van desde la compra de bienes y servicios con rubros destinados a otros gastos del Estado, hasta permitir el envío de más de un proyecto de ley con el carácter de urgente en materia económica (Constitución de la República de Ecuador, art. 140) y la movilización de la policía y las fuerzas armadas con amplias facultades. Realidad planteada en textos académicos, en noticias y en artículos doctrinales. Cito a continuación a Juan Pablo Aguilar Andrade (2010) (artículo bastante diciente para quienes deseen ampliar la labor de la Corte como órgano de justificación de estados de excepción en ese país):

... ciento setenta y nueve estados de excepción se han decretado desde el inicio del último periodo democrático hasta la promulgación de la Constitución vigente; de ellos ciento treinta y dos (las tres cuartas partes), son posteriores al año 2000. Durante la presidencia de Rafael Correa, y hasta el 20 de octubre de 2008, se decretaron cuarenta y ocho estados de excepción, lo que casi alcanza los cincuenta y seis que sumaron sus 
dos antecesores. Parece claro, sobre todo en el período reciente, que la excepción se ha convertido en la regla.

Así, desde 2007 a la fecha se han declarado 102 estados de excepción, en proporción de 7,84 declaratorias por año. En el gobierno del expresidente Rafael Correa (2007-2017), por ejemplo, se dieron 89 de ellos basados en "emergencias" distintas. Tal es el caso de agosto de 2015, cuando hizo erupción el volcán Cotopax (hecho aprovechado para disolver las convocatorias masivas de los sectores indígenas), o en el 2010, el llamado "30s", se realizó la declaratoria motivada por una protesta policial, seguida de disturbios que permitieron el arresto de 300 agentes, luego de que Correa afirmara que se trató de un golpe de Estado encubierto.

Entre 2007 y 2009, Correa firmó seis decretos de estados de excepción o su renovación, cinco de ellos de Petroecuador y sus filiales y uno por el virus de la influenza porcina en todo el territorio; de 2009 a 2013, Correa suscribió 67 decretos por diversos motivos: eléctricos, hídricos, erupciones volcánicas, la temporada invernal, sanidad, la revuelta policial del 30 de septiembre, entre otros. De 2013 a 2017 se dieron 16 decretos sobre estados de excepción, entre declaratorias y renovaciones; en este periodo destacan los que tuvieron su origen en el terremoto del 16 de abril de 2016, cuya última renovación se realizó ya en el gobierno de Lenín Moreno el 13 de julio de 2017.

Por otro lado, con el presidente Moreno se firmaron por lo menos trece decretos sobre estados de excepción sobre distintos temas, y ya en este 2020 encontramos el más reciente, motivado por la crisis de la pandemia ocasionada por el covid-19, el cual sirvió como base para que el gobierno ecuatoriano expidiera más de un centenar de medidas. De esta manera lo resaltan los periódicos locales como el diario El Universo (2019) en su artículo "Suman 101 decretos de estados de excepción y renovación desde 2007 en Ecuador".

Ahora bien, en aras de completar aún más los datos mencionados, cabe mencionar que ninguna de esas declaratorias que mantuvieron al pueblo en permanente estado de excepción fue declarada inconstitucional, pese a que, por ejemplo, en el "30s" se adoptó como medida que solo los medios oficiales podrían reportar los hechos, lo que constituyó una flagrante vulneración a la libertad de prensa.

El diario El Comercio.com de Ecuador (2020), así como la mayoría de los medios locales, informaron sobre la última declaratoria de estado de emergencia, aquella motivada por el covid 19 en ese país, de donde pueden extraerse los siguientes datos:

Notificación Oficial y Declaratoria: 16 de marzo de 2020, mediante el Decreto Ejecutivo 1017 firmado por el presidente Lenín Moreno.

La Corte Constitucional dio su dictamen favorable el 20 de marzo y recomendó que "las autoridades deben sujetarse a las competencias y atribuciones expresamente conferidas por la Constitución y la Ley".

Ahora bien, del Decreto Ejecutivo 1017 pueden analizarse los siguientes elementos de control formal de acuerdo con la LOGJCC: 
- Identificación de los hechos y de la causal constitucional que se invoca: la causal fue calamidad pública, motivada por: los casos de coronavirus confirmados y la Declaratoria de pandemia de covid-19 por parte de la Organización Mundial de la Salud (oms).

- Justificación de la declaratoria: alto riesgo de contagio, afectación de los derechos a la salud y a la convivencia pacífica, necesidad de controlar la situación de emergencia sanitaria para garantizar los derechos de las personas ante la presencia del virus (art. 1).

- Ámbito territorial y temporal de la declaratoria: en todo el territorio del Ecuador.

- Derechos que sean susceptibles de limitación: libertad de tránsito y libertad de asociación.

En cuanto a las medidas adoptadas dentro del decreto, se resaltan:

1. Movilizar a la Policía Nacional, las fuerzas armadas, el Ministerio de Salud Pública y el Servicio Nacional de Gestión de Riesgos y Emergencias, cada uno en sus competencias, para restablecer el orden público, colaborar en el control de la limitación de derechos y, en general, ejecutar las acciones necesarias para mitigar los efectos del coronavirus.

2. Suspender los derechos a la libertad de tránsito, de asociación y de reunión, a través de horarios y mecanismos dispuestos por el Comité de Operaciones de Emergencias Nacional. Salvo las excepciones contempladas y en grupos poblacionales de alto riesgo.

3. Cuarentena Nacional Sanitaria, aislamiento obligatorio y toque de queda a partir del 17 de marzo.

4. Suspender la jornada presencial de trabajo del 17 al 24 de marzo, adoptando el teletrabajo, excepto para la prestación de servicios públicos, la actividad industrial, comercio, salud, ganadería y cuidado de animales.

5. Disponer las requisiciones para mantener los equipos necesarios (en caso de extrema necesidad) y cumpliendo con la totalidad de los requisitos legales, las formalidades y la documentación necesaria.

6. Recursos obtenidos por provisión del Ministerio de Economía y Finanzas.

7. Duración: 60 días.

El 16 de mayo se declaró la prórroga o extensión del estado de excepción a través del Decreto Ejecutivo 1502, por 30 días que culminan el 16 de junio de 2020.

Por último, la tabla 3 muestra el comportamiento de los decretos en el marco del estado de excepción durante la actual crisis del covid-19 en Ecuador: 
Tabla 3. Decretos emitidos en el ESTAdo de EXCEPCión POR COVID-19

\begin{tabular}{|c|c|c|}
\hline $\begin{array}{c}\text { Fecha de } \\
\text { promulgación }\end{array}$ & Asunto del decreto & Número \\
\hline $16 / 03 / 2020$ & Declaratoria de estado de excepción & Decreto 1017 \\
\hline $21 / 03 / 2020$ & Renuncia ministros Salud y Trabajo & Decreto 1018 \\
\hline $22 / 03 / 2020$ & Establecer como zona especial de seguridad a la provincia del Guayas & Decreto 1019 \\
\hline $27 / 03 / 2020$ & Sobre Reglamento para la aplicación de la Ley de Régimen Tributario Interno & Decreto 1021 \\
\hline $27 / 03 / 2020$ & Sobre Bono de Protección Familiar por Emergencia Sanitaria & Decreto 1022 \\
\hline $23 / 04 / 2020$ & Cambios en el gabinete & Decreto 1025 \\
\hline $04 / 05 / 2020$ & Cambios en el gabinete & Decreto 1031 \\
\hline 05/05/2020 & Adquisición de fármacos y otros bienes estratégicos de salud & Decreto 1033 \\
\hline 08/05/2020 & Reducción de sueldos del presidente, vicepresidente, ministros y viceministros & Decreto 1041 \\
\hline $09 / 05 / 2020$ & Suprímase la Secretaría Técnica de las Juventudes & Decreto 1044 \\
\hline $09 / 05 / 2020$ & $\begin{array}{l}\text { Extinción de las Empresas Públicas de Fármacos, Fabricamos Ecuador Fabrec } \\
\text { EP y Cementera del Ecuador }\end{array}$ & Decreto 1045 \\
\hline $11 / 05 / 2020$ & $\begin{array}{l}\text { Aclaración de la reducción de sueldos del presidente, vicepresidente, minis- } \\
\text { tros y viceministros }\end{array}$ & Decreto 1047 \\
\hline $15 / 05 / 2020$ & $\begin{array}{l}\text { Renovar el estado de excepción por calamidad pública en todo el territorio } \\
\text { nacional }\end{array}$ & Decreto 1052 \\
\hline $19 / 05 / 2020$ & $\begin{array}{l}\text { Reformar el Reglamento General a la Ley Orgánica del Sector Público en lo } \\
\text { atinente a las jornadas especiales en el Sector Público }\end{array}$ & Decreto 1053 \\
\hline $19 / 05 / 2020$ & $\begin{array}{l}\text { Reformar el Reglamento de Regulación de precios de derivados de petróleo } \\
\text { expedido mediante Decreto Ejecutivo 338, publicado en el Registro Oficial } \\
73 \text { de } 02 \text { de agosto de } 2005 \text {, considerando un nuevo sistema de precios de } \\
\text { mercado }\end{array}$ & Decreto 1054 \\
\hline $19 / 05 / 2020$ & $\begin{array}{l}\text { Suprímase el Servicio de Gestión Inmobiliaria del Sector Público y su } \\
\text { Directorio }\end{array}$ & Decreto 1064 \\
\hline
\end{tabular}

Fuente: Cámara de Industrias y Producción, Repositorio de documentos Emergencia covid-19 Ecuador (2020).

\section{Conclusiones}

Los estados de excepción son regímenes jurídicos que se estipulan dentro de los sistemas legislativos de los Estados para ser utilizados ante emergencias o, mejor, durante momentos de anormalidad que no pueden afrontarse con las normas vigentes, así pues, obedecen a una necesidad y las medidas adoptadas deben corresponder a la misma.

A través de la historia, el estado de excepción ha suscitado diferentes análisis que nutren su concepto y que, ajustados al contexto, dan profundidad a la figura, lo cual nos lleva a cuestionar su aplicación como herramienta de solución y a ver que, en ocasiones, 
no protege al Estado y a los derechos de los ciudadanos, sino al orden establecido, al poder vigente y a quien lo detente.

El dictador, el soberano o el Ejecutivo son los depositarios de esas facultades extraordinarias, constituyen el sujeto revestido de potestades que declara y da contenido al régimen, actuando como legislativo y emitiendo decretos que con fuerza de ley tienden a solucionar la crisis.

Las circunstancias que motiven el estado de sitio deben estar contempladas en el ordenamiento constitucional de cada Estado y deben revestir tal carácter que los asociados o ciudadanos, en pro de solucionarlas, limiten sus libertades para proteger un derecho de mayor envergadura.

El DIH ha dado estructura y limitantes a los estados de emergencia, a tal punto que determina (ya no por capricho del dictador) cuáles son los derechos que pueden o no ser suspendidos o restringidos durante la vigencia de los mismos; asimismo, ha establecido protocolos de notificación y veeduría que rigen en la actualidad.

En los últimos tiempos, Ecuador ha vivido de cerca las declaratorias de estado de excepción, y es la normalidad en su legislación (lo normal que debería ser lo anormal); la Constitución de 2008 los estipula y determinó sus alcances a grandes rasgos; la ley ha desarrollado algunos aspectos. Asimismo, la Corte Constitucional también naciente de la Constitución los "controla”, pero adolece de una ley orgánica que los desarrolle con mayor profundidad e hile delgado en su regulación, tal vez por eso el abuso del régimen es tan frecuente.

La pandemia producida por el covid-19 llevó al mundo y sus sistemas a implementar estrategias y a cambiar la dinámica de vida, impactando a las personas, las familias y, en general, a las organizaciones político-administrativas, por eso la mayoría de los Estados acudieron a la declaratoria de los estados de excepción, lo que conllevó medidas como el aislamiento, la cuarentena y el toque de queda, que son restricciones a derechos de los asociados, pero, también, aquellas tendientes a reubicar, obtener y ejecutar recursos para atender la emergencia. Ecuador no fue la excepción.

Ahora bien, en las culturas jurídicas latinoamericanas, el estado de sitio ha "permitido" el abuso de poder y graves perjuicios al pueblo, por ello el control político y constitucional son muy importantes en su vigencia, pero a través de los mecanismos de participación ciudadana podrían darse espacios de control para que la ciudadanía en general ejerza una suerte de limitación al poder que se configura en los estados de excepción. No obstante, sería necesaria una población interesada, informada, crítica y analítica, que se aleje de subjetividades y analice objetivamente cada uno de los elementos de la figura, lo que de nuevo nos lleva a una educación cívica política y de derechos generalizada que, por ahora, en vez de ser generalizada, se ve recortada al interior de nuestros países.

La corrupción y el abuso de poder a través de los estados de excepción nos pone de nuevo ante la recomendación general de elegir "correctamente" y de entender la magnitud del mandato que ejercemos con el sufragio, de tener en cuenta la trayectoria, capacitación 
y, más aún, la formación de los candidatos; debemos hacer elecciones inteligentes para evitar catástrofes peores en el marco de una emergencia.

\section{Referencias}

Agamben, G. (2013). Homo sacer: el poder soberano y la nuda vida. Pre-Textos.

Aguilar, J. (2010). Entre la retórica de lo nuevo y la persistencia del pasado: la Corte Constitucional y los estados de excepción. Iuris dictio, 13(10).

Cámara de Industrias y Producción (2020). Repositorio de documentos emergencia COVID-19 Ecuador. Cámara de Industrias y Producción.

El Comercio (2020, 16 de abril). ¿Qué pasó en un mes de estado de excepción por el covid-19 en Ecuador? El comercio. https://www.elcomercio.com/actualidad/coronavirus-ecuador-mes-excepcion-emergencia.html

ElUniverso(2019,7 deoctubre).Suman 101 decretosdeestadosdeexcepcióny renovacióndesde 2007 en Ecuador. El Universo. https://www.eluniverso.com/noticias/2019/10/07/ nota/7550306/suman-101-decretos-estados-excepcion-renovacion-200

Fijalkowski, J. (1966). La trama ideológica del totalitarismo: análisis crítico de los componentes ideológicos de la filosofía política de Carl Schmitt. Tecnos.

Gerhard, V. (2003). Politik als Ausnahme Der Begriff des Politischen als dekontextualisierte Antitheorie. En R. Mehring (Ed.), Carl Schmitt Der Begriff des Politischen (pp. 205-218). Akademie Verlag.

Haba, E. (1986). Tratado básico de derechos humanos (tomo II). Juricentro.

Martínez, W. (2009). La dictadura como encarnación de lo político: anotaciones en torno a Carl Schmitt. Estudios Políticos, 34, 47-62.

Oficina del Alto Comisionado de las Naciones Unidas para los Derechos Humanos (OACNDH) (2013). Los estados de excepción en el marco del Derecho Internacional de los Derechos Humanos. Boletín 23. https://www.oacnudh.org.gt/estandares/docs/ Boletines/boletin23.pdf.

Organización de los Estados Americanos (OEA) (1969). Convención Americana sobre Derechos Humanos. Conferencia Especializada Interamericana sobre Derechos 
Humanos. OEA. http://www.oas.org/dil/esp/tratados_B-32,Convencion_Americana_sobre_Derechos_Humanos.pdf

Pardo, O. (2011). Los estados de excepción en el constitucionalismo evolucionario: el caso colombiano. Revista Dixi, 13(14), 71-87.

Pavlovich, G. (2008). El estado de excepción: la tensión entre la política y el derecho. Justicia Juris, 10, 37-49.

Presidencia de la República del Ecuador (2008). Constitución de la República del Ecuador. Registro Oficial 449.

Real Academia de la Lengua Española (2019). Extraordinario. https://dle.rae.es/ extraordinario

Schmitt, C. (1922). Teología política. En H. O. Aguilar, Carl Schmitt, teólogo de la política. Fondo de Cultura Económica.

Silva, R. (2016). Los estados de excepción como legitimación de un estado de cosas inconstitucional: expresión del seudoconstitucionalismo. Revista Eleuthera, 15, 4658. DOI: 10.17151/eleu.2016.15.4.

\section{Normativa}

Ley de Seguridad Pública y del Estado de Ecuador, 22 de octubre de 2010. RO № 306.

Ley Orgánica de Garantías Jurisdiccionales y Control Constitucional de Ecuador, 22 de octubre de 2009. RO - Supl. 52.

\section{Jurisprudencia}

Corte Constitucional de Ecuador, Sentencia 001-08-SEE-CC, Caso 0001-08-EE (04 de diciembre de 2008).

Fecha de recepción: 16 de junio de 2020

Fecha de aprobación par 1: 18 de agosto de 2020

Fecha de aprobación par 2: 02 de julio de 2020 